\title{
CHANGES IN REAL SURFACE AREA, CRYSTALLOGRAPHIC ORIENTATION AND MORPHOLOGY OF PLATINUM ELECTRODES CAUSED BY PERIODIC POTENTIAL TREATMENTS: PHENOMENOLOGICAL APPROACH
}

\author{
A. VISINTIN, J.C. CANULLO, W.E. TRIACA and A.J. ARVIA \\ Instituto de Investrgaciones Fistcourimicas Ténicas y Aphcadas (INIFTA), Facultad de Cienctas Exactas, \\ Unversidad Nacional de La Plata, Casilla de Correo 16, Stcursal 4, 11900) La Plata (Argentma)
}

(Received 7th May 1987: in revsed form 13th August 1987)

\begin{abstract}
ABSTRAC: $\Gamma$
The changes in surface structure of polyfaceted single crystal platinum spheres subjected to repetitive square-wave potential treatments in acid solution have been studied. The dependence of the prevailing type of change on symmetry, potential limits and frequency of the periodic potential has been determined. Results are discussed on the basis of different reactions occurring within definte potential windows and distinct rate controlling processes depending on the operating conditions. Accordingly, the surface restructuring involves a predominant change in either the real surface area, the crystallographic orientation or the entire surface morphology.
\end{abstract}

\section{(1) INTRODUCTION}

It is well known that the surface of fcc metal electrodes immersed in aqueous solutions can be modified substantially in different ways through the application of periodic potentials of various waveforms, that is, by increasing the real surface area [1-7], by changing the relative proportion of crystallographic faces through a process denoted as electrochemical faceting [7-11] and by producing some particular surface morphologies $[4,10,12]$. The prevailing type of change depends principally on the characteristics of the periodic potential, and secondarily on the waveform and the electrolyte composition [7,11]. It is also possible to accomplish a combined effect such as development of a certain type of preferred crystallographic orientation and simultaneously a substantial increase in real surface area [13]. These results offer for the first time the possibility of a rational handling of the two most important characteristics of the surface of metal electrodes, namely, type and quantity of reacting sites, through an electrode treatment under definite operating conditions. 
At this stage it is important to establish the most suitable conditions for producing a particular type of change in the surface structure of metal electrodes for attempts to correlate the latter to the electrochemical response of the treated electrodes. The present paper is devoted mainly to the phenomenology associated with the periodic potential treatment of platinum electrodes covering a wide range of operating conditions.

\section{(II) EXPERIMENTAL}

Runs were made in $1 \mathrm{M} \mathrm{H}_{2} \mathrm{SO}_{4}$ at $25^{\circ} \mathrm{C}$ with polyfaceted single crystal (sc) platinum (Johnson Matthey Chem. Co.) spheres of $0.01-0.04 \mathrm{~cm}^{2}$ geometric area as working electrodes. The polyfaceted sc platinum spheres were prepared by melting the end of $0.5 \mathrm{~mm}$ diameter platinum wires with a small oxygen-gas torch flame, followed by cooling in air. The symmetry and distribution of the principal crystallographic poles of the resulting surfaces were followed through optical microscopy and SEM images [14,15]. The potential of the working electrode was measured against a RHE in acid electrolyte. A large area platinum counterelectrode concentrically surrounding the working electrode was used. The electrochemical cell and the instrumentation were described elsewhere [11].

Prior to each experiment the working electrode was potential cycled at $0.1 \mathrm{~V} / \mathrm{s}$ between $0.05 \mathrm{~V}$ and $1.50 \mathrm{~V}$ for a few cycles to attain a stabilized voltammogram. Later, the working electrode was subjected to a repetitive square wave potential signal (RSWPS) between lower $\left(E_{1}\right)$ and upper $\left(E_{\mathrm{u}}\right)$ potential limits at a certain frequency $(f)$ during a preset time $(t)$. The duration of each potential step, $\tau_{1}$ and $\tau_{u}$, was adjusted at convenience. The ratio $\tau_{\mathrm{u}} / \tau_{1}=1$ determines a symmetric wave, whereas $\tau_{u} / \tau_{1} \neq 1$ corresponds to asymmetric waves. After the RSWPS treatment, voltammograms were run in the $0.05 \mathrm{~V}-0.60 \mathrm{~V}$ and/or in the $0.05 \mathrm{~V}-1.50 \mathrm{~V}$ range at $0.1 \mathrm{~V} / \mathrm{s}$.

The relative increase in surface area $(R)$ of the resulting surface was determined voltammetrically through either the corresponding $\mathrm{H}$-adatom monolayer charge or the electroreduction charge of the $\mathrm{O}$ monolayer, before and after application of the RSWPS treatment.

The degree of development of a preferred crystallographic orientation of the treated surface associated with reacting sites favouring the electrosorption of strongly adsorbed $\mathbf{H}$ atoms (s.a.H) was followed voltammetrically through the ratio between the height of the strongly adsorbed $\mathbf{H}$ electrooxidation current peak $\left(h_{2}\right)$ and the height of the weakly adsorbed $\mathrm{H}$ electrooxidation current peak $\left(h_{1}\right)$. The average $h_{2} / h_{1}$ ratio for the initial polyfaceted sc platinum spheres was ca. 0.64 .

Likewise, the degree of development of a preferred crystallographic orientation associated with reacting sites favouring the electrosorption of weakly adsorbed $\mathrm{H}$ atoms (w.a.H) was given arbitrarily in terms of the $h_{1} / h_{2}$ ratio. The average $h_{1} / h_{2}$ ratio for the initial polyfaceted sc spheres was ca. 1.56 .

The electrochemical measurements were complemented with SEM micrographs of the treated surfaces. 


\section{(III) RESULTS}

To facilitate comprehension of the results, these are grouped on the basis of the following criterion. Firstly, results obtained from a symmetric periodic potential treatment covering two potential regions, one related to the development of reacting sites for s.a.H electrosorption and another one related to the promotion of reacting sites for w.a.H electrosorption, are shown. Secondly, results obtained under an asymmetric periodic potential treatment are considered similarly.

(III.1) Changes produced by a symmetric RSWPS for $E_{l}=0.05 \mathrm{~V}$ and $E_{u}=1.50 \mathrm{~V}$ in the $0.025 \mathrm{kHz} \leqslant f \leqslant 7 \mathrm{kHz}$ range

The main effects produced by the symmetric RSWPS treatment of platinum electrodes in the $0.05 \mathrm{~V}-1.50 \mathrm{~V}$ range are an increase in real surface area, as measured through $R$, and the development of reacting sites for s.a.H electrosorption, as followed through the $h_{2} / h_{1}$ ratio. The variation of these two electrode characteristics depends on the frequency and duration of the RSWPS, as seen in Fig. 1. For $f=0.025 \mathrm{kHz}$ the increase of $R$ with time involves an induction time of about $2 \mathrm{~h}$, and later a rapid increase presumably approaching a limiting value (not

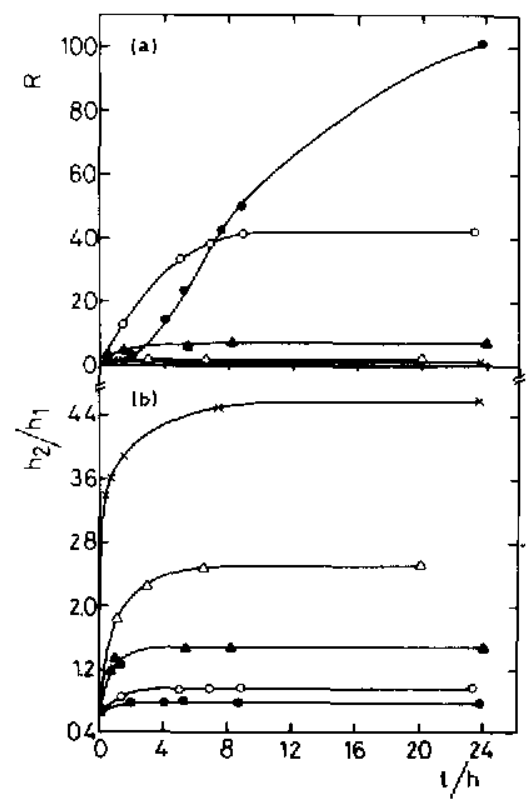

Fig. 1. Dependence of $R$ and $h_{2} / h_{1}$ on $t$ at different $f$ derived from voltammograms (third cycle) run at $0.1 \mathrm{~V} / \mathrm{s}$ between $0.05 \mathrm{~V}$ and $0.60 \mathrm{~V}$ in $1 \mathrm{M} \mathrm{H}_{2} \mathrm{SO}_{4}, 25^{\circ} \mathrm{C}$, after RSWPS treatment $\left(E_{1}=0.05 \mathrm{~V}\right.$, $\left.E_{\mathrm{u}}=1.50 \mathrm{~V}\right) . f=(\bullet) 0.025,(O) 0.1,(\Delta) 1,(\Delta) 3,(\times) 7 \mathrm{kHz}$. 
shown in the figure) for $t>24 \mathrm{~h}$. When $0.1 \mathrm{kHz} \leqslant f \leqslant 3 \mathrm{kHz}, R$ increases monotonically on increasing $t$, approaching a clear limiting value. Practically no increase in $R$ can be noticed for $f=7 \mathrm{kHz}$. Correspondingly, the $h_{2} / h_{1}$ ratio shows a fast increase at $t \rightarrow 0$ for $f \geqslant 1 \mathrm{kHz}$. Later it reaches a plateau at a certain time which increases according to $f$. In order to investigate the influence of $f$ on the different effects, the duration of the RSWPS was fixed in the $10-24 \mathrm{~h}$ range. Within this lapse of timc either a limiting value of $R$, at least for $f \geqslant 0.1 \mathrm{kHz}$, or a plateau of the $h_{2} / h_{1}$ ratio in the entire $f$ range can be observed (Fig. 1).

The RSWPS treatment under the above preset conditions produces remarkable changes in the voltammetric response of the treated surfaces as well as in the corresponding surface morphologies as compared to the blank (Figs. 2-6). These changes are strongly frequency dependent. At the lowest frequency, that is, $f=0.025$ $\mathrm{kHz}(t=23.8 \mathrm{~h})$, a remarkable increase in the $\mathrm{H}$-adatom electrosorption charge of the treated platinum surface can be noticed (Fig. 2a). The resulting value of $R$ is 102. Likewise, the relative distribution of voltammetric peaks, as compared to the blank, is modified only slightly in the direction expected for an extra contribution of reacting sites for s.a.H electrosorption, that is, $h_{2} / h_{1}=0.76$. The SEM images of the treated surface show the growth of a dendritic metal layer on the entire electrode surface (Figs. $2 \mathrm{~b}, \mathrm{c}$ ). In this case, the dendrites exhibit a remarkable branched structure (Fig. 2c). It must be noticed that at the earlier stages of the metal layer's growth, some influence of the different crystallographic planes of the substrate on the morphological features of the metal layer can clearly be appreciated (Figs. $3 \mathrm{a}-\mathrm{d})$. Thus, for RSWPS treatment $\left(E_{1}=0.05 \mathrm{~V}, E_{\mathrm{u}}=1.55 \mathrm{~V}, f=0.025 \mathrm{kHz}\right)$ lasting $1 \mathrm{~h}$, the voltammetric response of the treated surface becomes only slightly modified as compared to the blank (Fig. 3a) but the corresponding SEM image of the region around the [100] crystallographic pole shows pyramide-shaped crystallites (Fig. 3c), most of them as individual growing centers, whereas the region around the [111] crystallographic pole already exhibits the net formation of a dendritic metal layer (Fig. 3d).

Similar runs made at $f=0.1 \mathrm{kHz}(t=23.3 \mathrm{~h})$ show the same effects as described for the lower frequency. However, in this case the value of $R$ turns out to be 42 and a clear trend to develop reacting sites for s.a.H electrosorption $\left(h_{2} / h_{1}=1.0\right)$ can be observed (Fig. 4a). Furthermore, the dendritic metal layer produced in this case, although it covers the electrode surface completely, approaches more closely a spike-like structure (Figs. 4b,c).

Otherwise, for $f=1 \mathrm{kHz}(\mathrm{t}=24 \mathrm{~h})$ the main effect is the development of reacting sites for s.a.H electrosorption $\left(h_{2} / h_{1}=1.5\right)$ with a minor increase in surface area, $R=7$ (Fig. 5a). In this case, the SEM image of the treated surface shows the absence of dendritic layer formation (Fig. 5b). The electrode surface, except the regions around the [111] crystallographic poles, becomes covered with faceted crystallites presumably involving reacting sites for s.a.H electrosorption (Figs. 5b,c). The greatest compactness of the crystallite layer is observed at the [110] crystallographic pole region, whereas an intermediate compactness is observed in the region around the [100] crystallographic poles (Fig. 5b). 

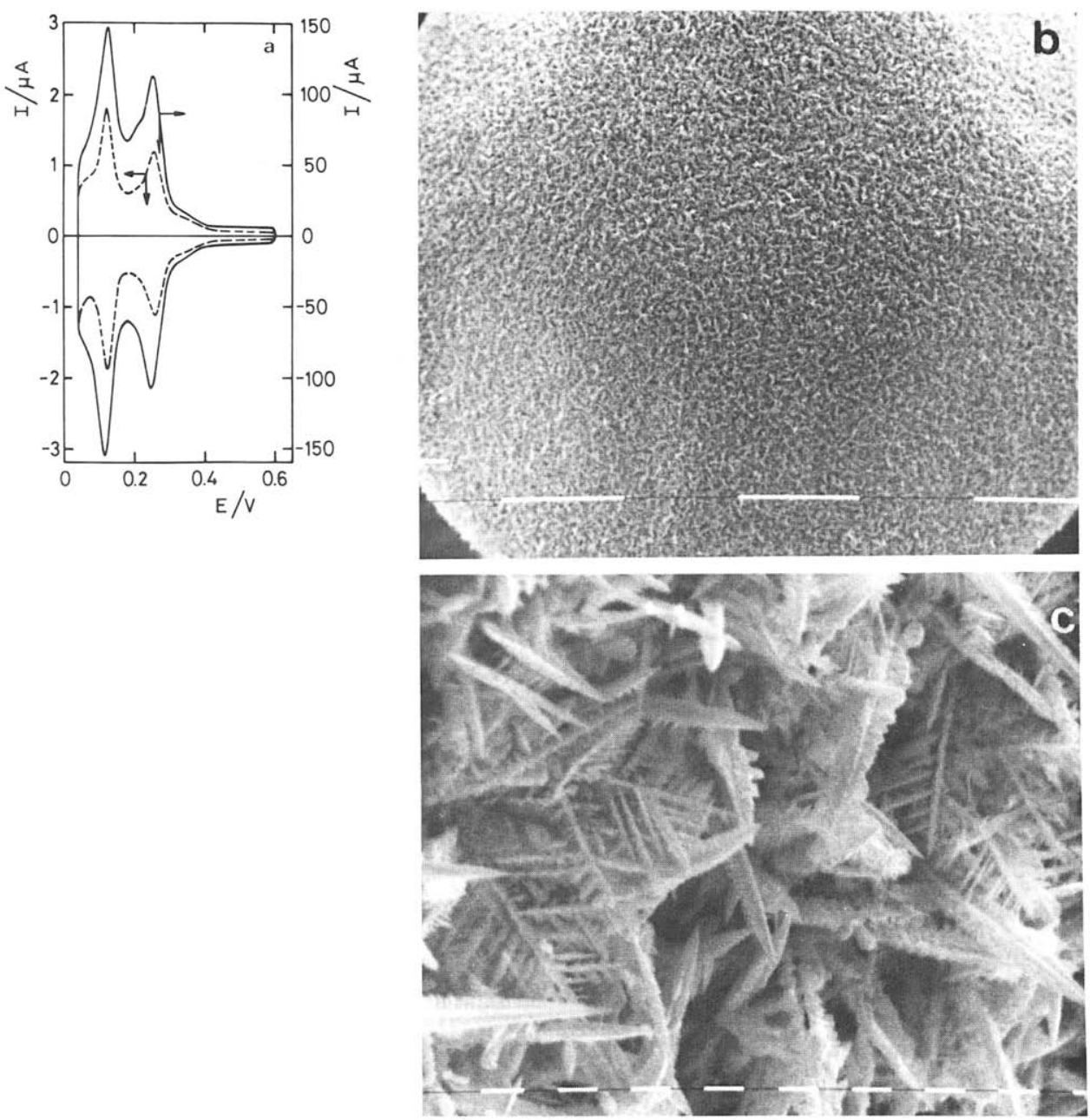

Fig. 2. Voltammograms run at $0.1 \mathrm{~V} / \mathrm{s}$ in $1 \mathrm{M} \mathrm{H}_{2} \mathrm{SO}_{4}, 25^{\circ} \mathrm{C}$, and SEM micrographs after $23.8 \mathrm{~h}$ RSWPS treatment ( $E_{1}=0.05 \mathrm{~V}, E_{\mathrm{u}}=1.50 \mathrm{~V}, f=0.025 \mathrm{kHz}$ ). (a) (—) Voltammogram (third cycle) run between $0.05 \mathrm{~V}$ and $0.60 \mathrm{~V}:(---)$ untreated polyfaceted sc platinum sphere. (b.c) SEM micrographs of the treated surface, scale: (b) $100 \mu \mathrm{m}$; (c) $1 \mu \mathrm{m}$.

Finally, for $f=6 \mathrm{kHz}(t=10 \mathrm{~h}$ ) only the development of reacting sites for s.a.H electrosorption $\left(h_{2} / h_{1}=3.73\right)$ and practically no increase in real surface area $(R=1.1)$ are noticed (Fig. 6a). In this case, the $\mathrm{H}$-adatom electrosorption voltammogram approaches those reported in the literature for either platinum (100) $\mathrm{sc}$ surfaces or platinum sc stepped with (100) narrow terraces under comparable conditions [16-19]. The SEM image of the treated electrode surface shows the absence of any type of crystallite layer (Fig. 6b). l'urthermore, the entire surface 

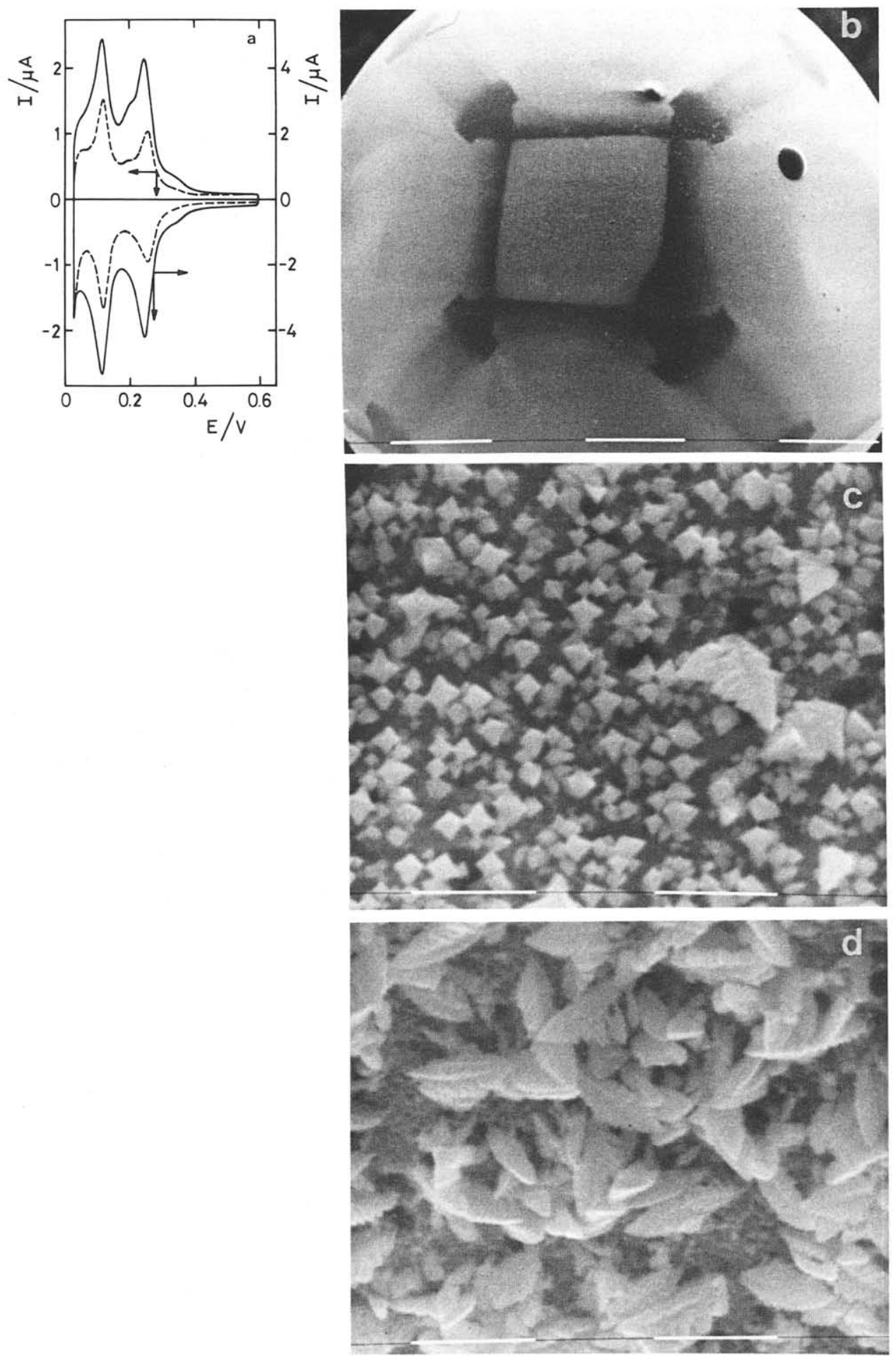

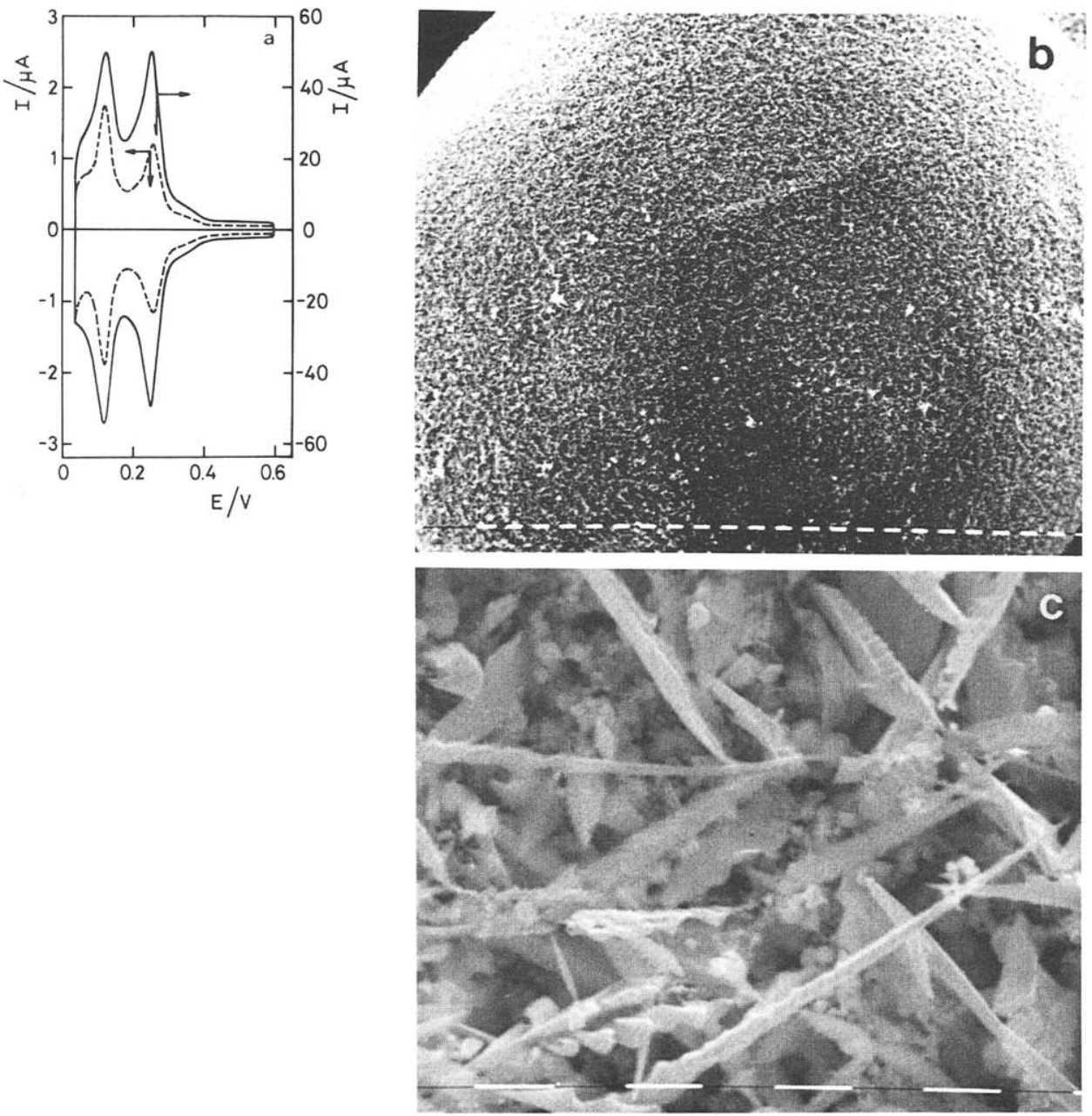

Fig. 4. Voltammograms run at $0.1 \mathrm{~V} / \mathrm{s}$ in $1 \mathrm{M} \mathrm{H}_{2} \mathrm{SO}_{4}, 25^{\circ} \mathrm{C}$, and SEM micrographs after $23.3 \mathrm{~h}$ RSWPS treatment $\left(E_{1}=0.05 \mathrm{~V}, E_{\mathrm{u}}=1.50 \mathrm{~V}, f=0.1 \mathrm{kHz}\right.$ ). (a) (- $(-)$ Voltammogram (third cycle) run between $0.05 \mathrm{~V}$ and $0.60 \mathrm{~V} ;(--$, ) untreated polyfaceted sc platinum sphere. (b,c) SEM micrographs of the treated surface, scale: (b) $10 \mu \mathrm{m}$; (c) $1 \mu \mathrm{m}$.

appears clearly faceted (Fig. 6c) with the characteristic fourfold macroscopic symmetry around the flat [100] crystallographic poles (Fig. 6b) as already described for single crystal platinum surfaces $[14,15]$.

Fig. 3. Voltammograms run at $0.1 \mathrm{~V} / \mathrm{s}$ in $1 \mathrm{M} \mathrm{H}_{2} \mathrm{SO}_{4}, 25^{\circ} \mathrm{C}$ and SEM micrographs after $1 \mathrm{~h}$ RSWPS treatment ( $E_{1}=0.05 \mathrm{~V}, E_{\mathrm{u}}=1.55 \mathrm{~V} ; f=0.025 \mathrm{kHz}$ ). (a) (—) Voltammogram (third cycle) run between $0.05 \mathrm{~V}$ and $0.60 \mathrm{~V} ;(--\infty)$ untreated polyfaceted sc platinum sphere. (b) SEM micrograph of the treated surface, scale $100 \mu \mathrm{m}$. (c) SEM micrograph of the region around the [100] crystallographic pole, scale $1 \mu \mathrm{m}$. (d) SEM micrograph of the region around the [111] crystallographic pole, scale $1 \mu \mathrm{m}$. 

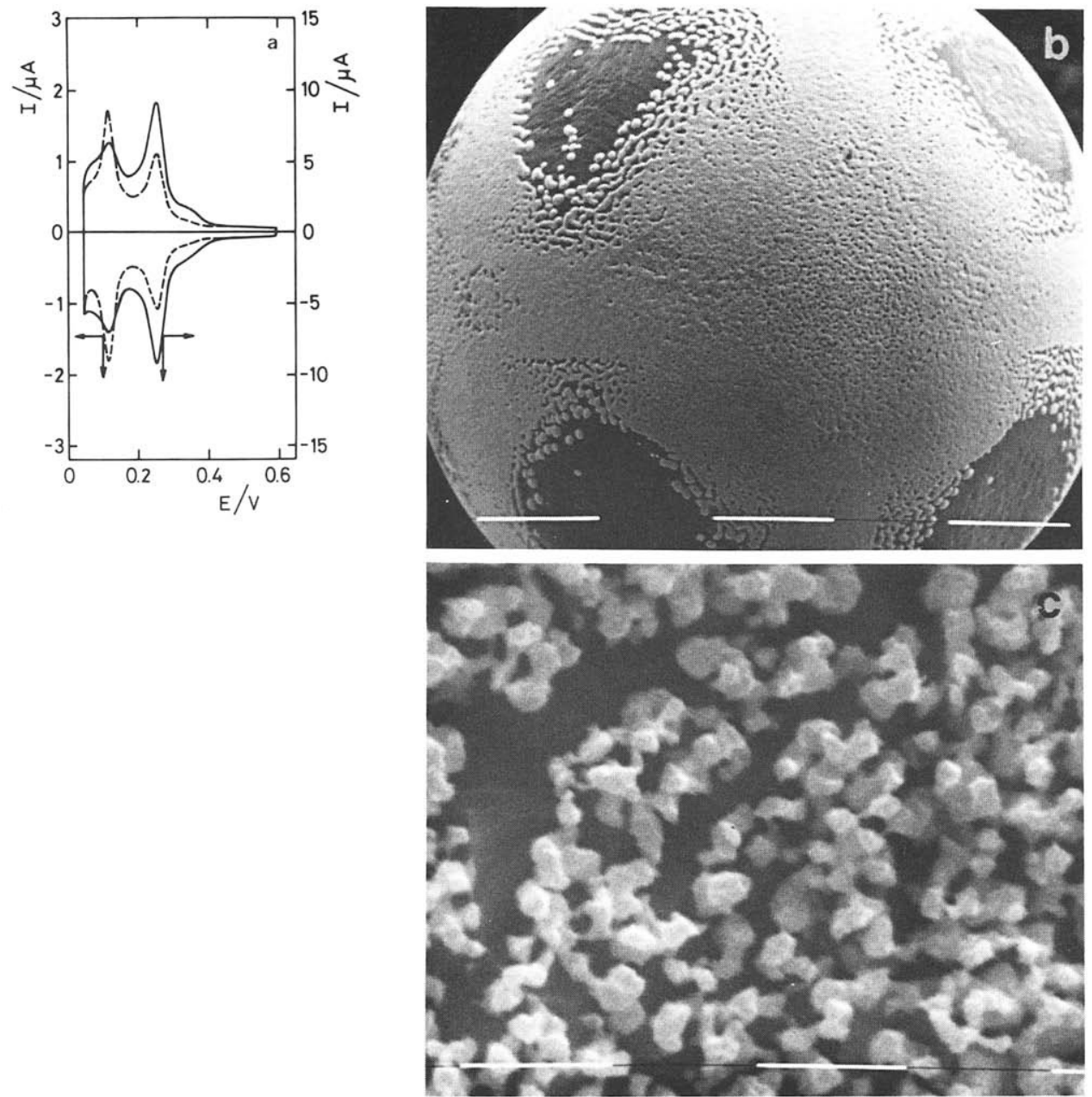

Fig. 5. Voltammograms run at $0.1 \mathrm{~V} / \mathrm{s}$ in $1 M \mathrm{H}_{2} \mathrm{SO}_{4}, 25^{\circ} \mathrm{C}$, and SEM micrographs after $24 \mathrm{~h}$ RSWPS treatment $\left(E_{1}=0.05 \mathrm{~V}, E_{\mathrm{u}}=1.50 \mathrm{~V}, f=1 \mathrm{kHz}\right.$ ). (a) (—) Voltammogram (third cycle) run between $0.05 \mathrm{~V}$ and $0.60 \mathrm{~V}$; (- - - ) untreated polyfaceted sc platinum sphere. (b) SEM micrograph of the treated surface, scale $100 \mu \mathrm{m}$. (c) SEM mocograph of the region around the [100] crystallographic pole, scale $1 \mu \mathrm{m}$.

(III.2) Changes produced by a symmetric RSWPS for $E_{i}=0.70 \mathrm{~V}$ and $E_{u}=1.35 \mathrm{~V}$ in the $0.25 \mathrm{kHz} \leqslant f \leqslant 7 \mathrm{kHz}$ range

Runs made at different values of $f$ covering the above-mentioned potential limits show changes of $R$ with time (Fig. 7a) which are substantially different from those depicted in Fig. 1a. These results provide for the first time some indications about possible different mechanisms according to the potential limits of the RSWPS. It 

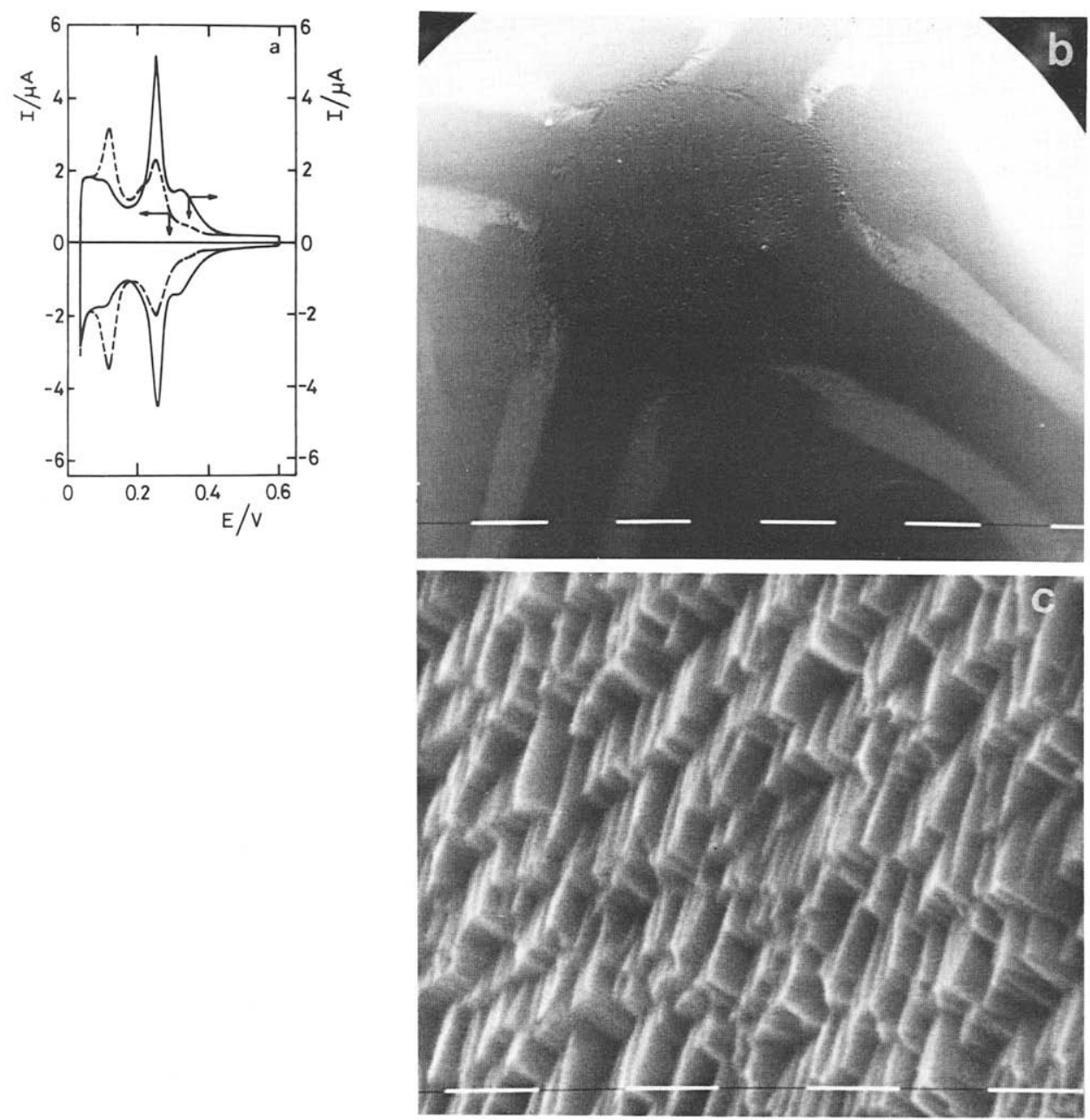

Fig. 6. Voltammograms run at $0.1 \mathrm{~V} / \mathrm{s}$ in $1 \mathrm{M} \mathrm{H}_{2} \mathrm{SO}_{4}, 25^{\circ} \mathrm{C}$, and SEM micrographs after $10 \mathrm{~h}$ RSWPS treatment ( $E_{1}=0.05 \mathrm{~V}, E_{\mathrm{u}}=1.50 \mathrm{~V}, f=6 \mathrm{kHz}$ ). (a) ( ) Voltammogram (third cycle) run between $0.05 \mathrm{~V}$ and $0.60 \mathrm{~V} ;(---)$ untreated polyfaceted sc platunum sphere. (b) SEM micrographs of the treated surface, scale $100 \mu \mathrm{m}$. (c) SEM micrograph of the region located between the [111] and [100] crystallographic poles, scale $1 \mu \mathrm{m}$.

should be noticed that for $f=0.25 \mathrm{kHz}$ a net increase in $R$ can be observed only after ca. $6 \mathrm{~h}$. At a constant time the greatest efficiency in increasing $R$ is observed for $f=1 \mathrm{kHz}$, and on further increasing $f$ the value of $R$ decreases. These changes of $R$ with $f$ are also accompanied by changes in the corresponding $h_{1} / h_{2}$ ratio (Fig. 7b) and surface morphology. For $f \geqslant 1 \mathrm{kHz}$, the $h_{1} / h_{2}$ ratio becomes greater than that for pc platinum [11], as is expected for the development of reacting sites for w.a.H electrosorption, and it attains a maximum value, which increases with $f$ 


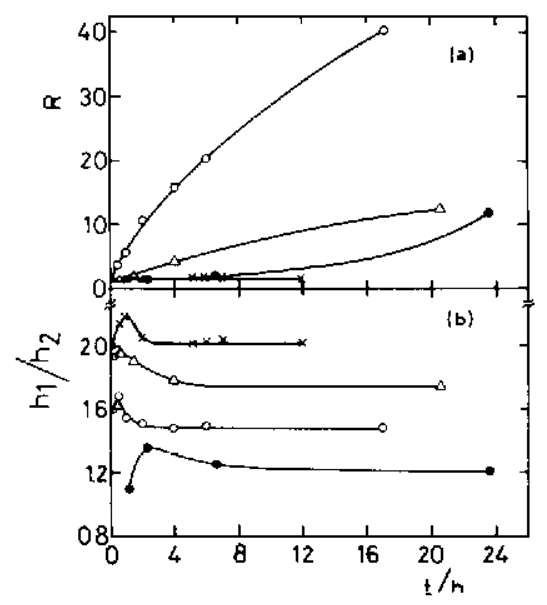

Fig. 7. Dependence of $R$ and $h_{1} / h_{2}$ on $t$ at different $f$ derived from voltammograms run at $0.1 \mathrm{~V} / \mathrm{s}$ following one cycle between $0.05 \mathrm{~V}$ and $1.50 \mathrm{~V}$ in $1 \mathrm{M} \mathrm{H}_{2} \mathrm{SO}_{4}, 25^{\circ} \mathrm{C}$, after RSWPS treatment $\left(E_{1}=0.70\right.$ $\left.\mathrm{V}, E_{\mathrm{u}}=1.35 \mathrm{~V}\right) . f=(\bullet) 0.25,(O) 1,(\Delta) 3,(\times) 7 \mathrm{kHz}$.

(Fig. 7b), at times shorter than $1 \mathrm{~h}$, in agreement with previous results [11]. The slow decrease in the $h_{1} / h_{2}$ ratio tending to a limiting value for $t \rightarrow \infty$ is presumably due to additional contributions to the electroreduction of the accumulated oxide layer related to the direct electrodeposition of dissolved platinum species from the solution. In order to have comparable data the following results correspond to electrodes which have been treated for $12-24 \mathrm{~h}$.

For $f=0.25 \mathrm{kHz}(t=23.6 \mathrm{~h})$ the $\mathrm{H}$-adatom electrosorption voltammogram of the treated surface (Fig. 8a) shows an increase in the voltammetric charge $(R=12)$ and its shape changes slightly compared to the voltammogram of the initial polyfaceted sc platinum surface. In this case, the $h_{1} / h_{2}$ ratio is equal to 1.2 and tends to that expected for a certain degree of development of reacting sites for s.a.H electrosorption. The treated surface, as revealed through SEM images, shows no crystallite layer formation but development of faceting, whose characteristics depend on the particular observation region (Fig. $8 \mathrm{~b}-\mathrm{d}$ ). Hence, one observes a relatively low increase in surface area as compared to that described in Section (III.1).

On the other hand, for $f=1 \mathrm{kHz}(17 \mathrm{~h})$, the voltammogram of the treated surface (Fig. 9a) shows a more remarkable increase in real surface area $(R=40)$ and significant changes in the relative distribution of $\mathrm{H}$-adatom voltammetric peaks in

Fig. 8. Voltammograms run at $0.1 \mathrm{~V} / \mathrm{s}$ in $1 \mathrm{M} \mathrm{H}_{2} \mathrm{SO}_{4}, 25^{\circ} \mathrm{C}$, and SEM micrographs after $23.6 \mathrm{~h}$ RSWPS treatment ( $E_{1}=0.70 \mathrm{~V}, E_{\mathrm{u}}=1.35 \mathrm{~V}, f=0.25 \mathrm{kHz}$ ). (a) (—) Voltammogram obtained after one cycle between $0.05 \mathrm{~V}$ and $1.50 \mathrm{~V} ;(-\ldots)$ untreated polyfaceted sc platinum sphere. (b) SEM micrograph of the treated surface, scale $100 \mu \mathrm{m}$. (c) SEM micrograph of the region around the [110] crystallographic pole, scale $10 \mu \mathrm{m}$. (d) SEM micrograph of the region located between the [111] and [100] crystallographic poles, scale $1 \mu \mathrm{m}$. 

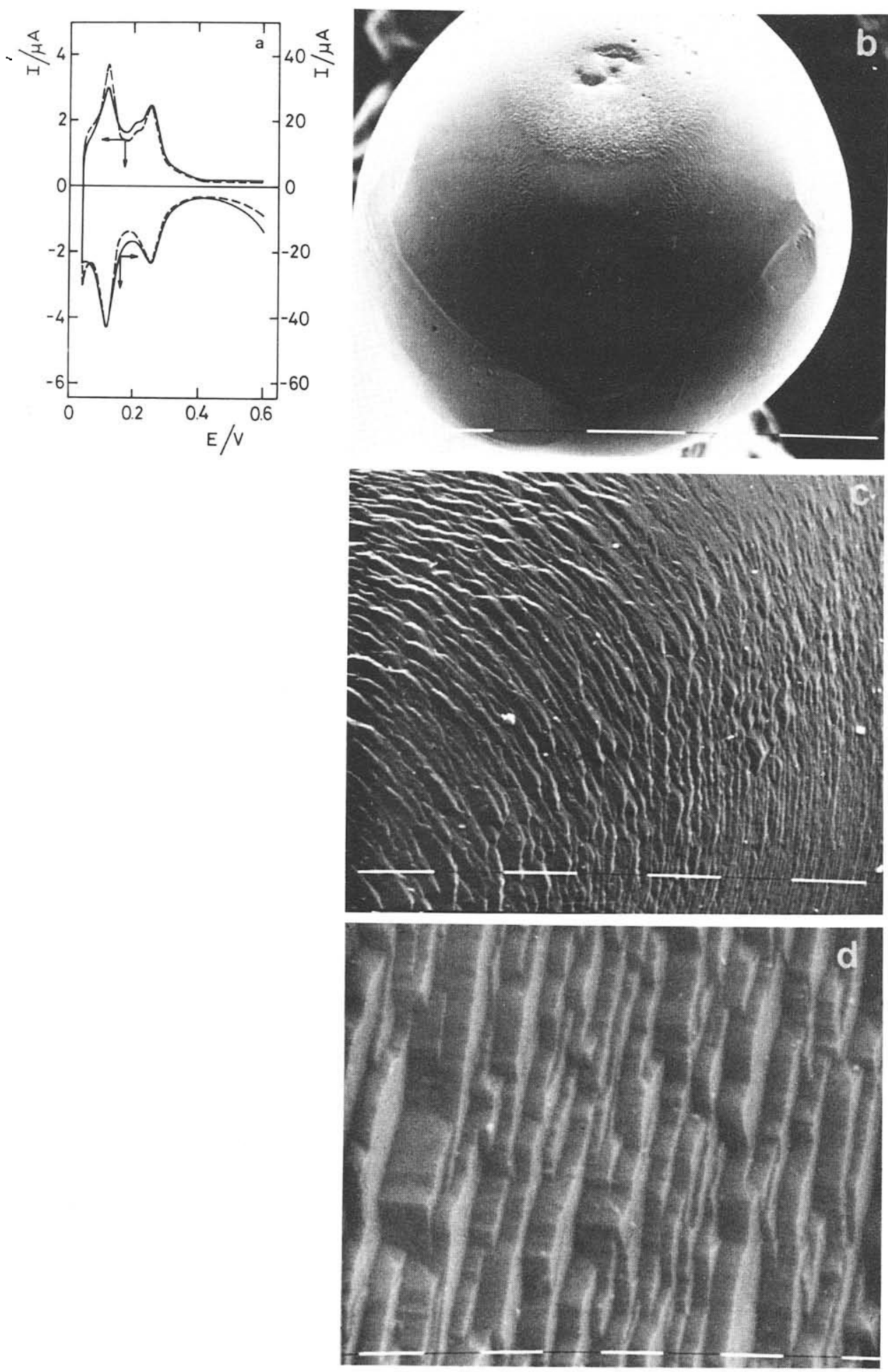

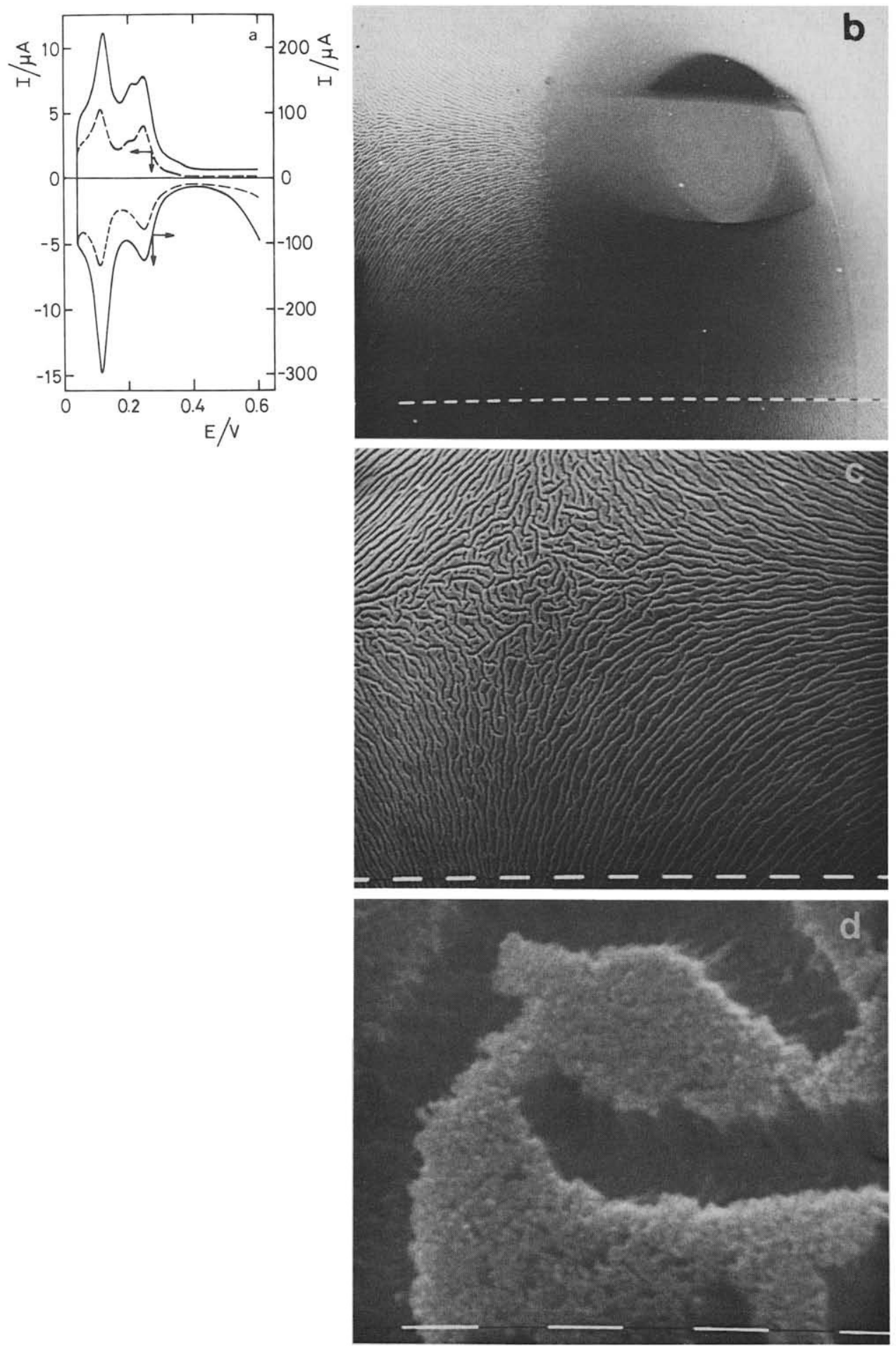

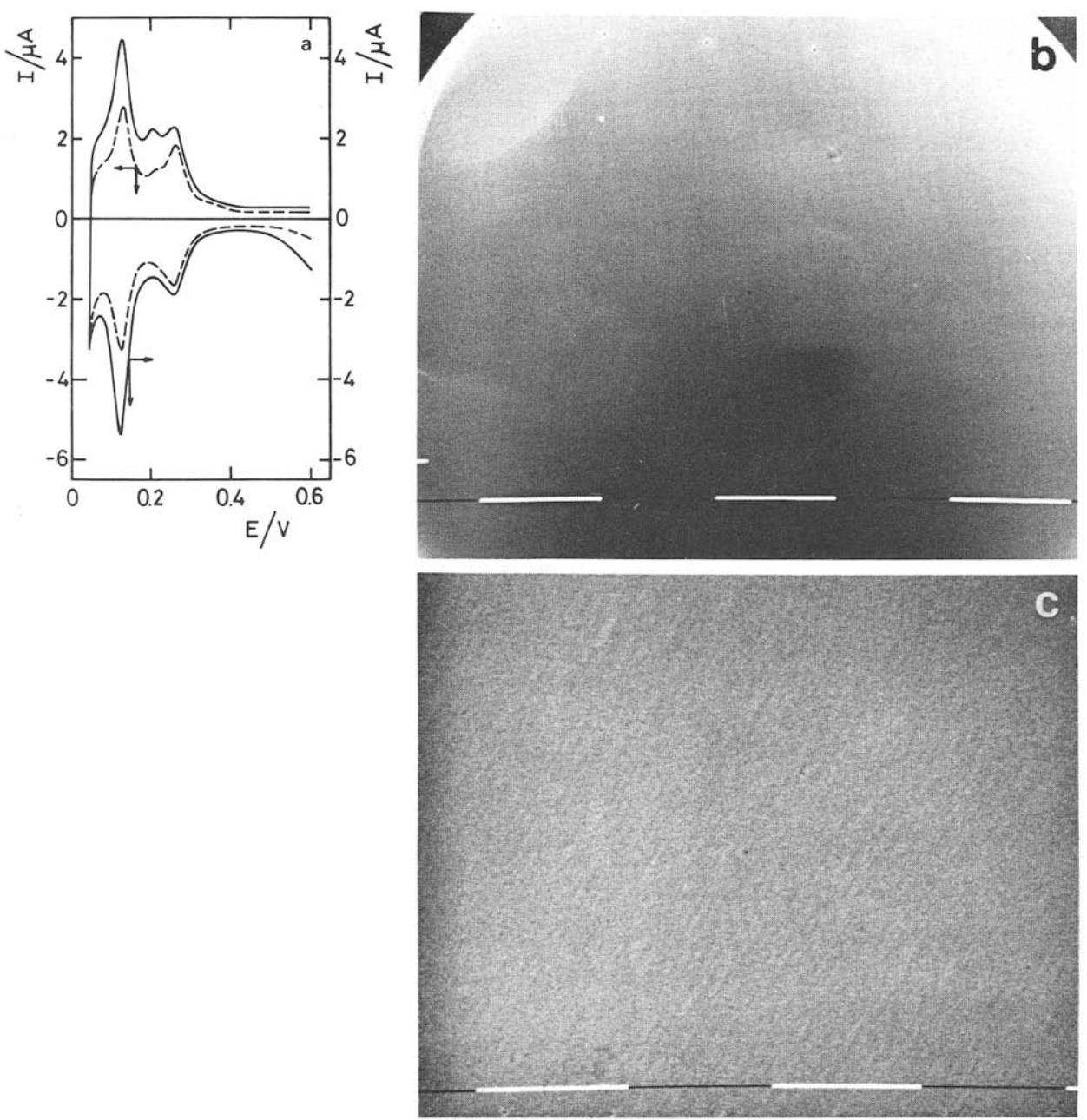

Fig. 10. Voltammograms run at $0.1 \mathrm{~V} / \mathrm{s}$ in $1 \mathrm{M} \mathrm{H}_{2} \mathrm{SO}_{4}, 25^{\circ} \mathrm{C}$, and SEM micrographs after $12 \mathrm{~h}$ RSWPS treatment ( $E_{1}=0.70 \mathrm{~V}, E_{\mathrm{u}}=1.35 \mathrm{~V}, f=7 \mathrm{kHz}$ ). (a) (—) Voltammogram obtaned after one cycle between $0.05 \mathrm{~V}$ and $1.50 \mathrm{~V}$; (- - ) untreated polyfaceted sc platinum sphere. (b) SEM micrograph of the treated surface, scale $100 \mu \mathrm{m}$. (c) SEM micrograph around the [100] crystallographic pole, scale $1 \mu \mathrm{m}$.

the direction expected for the development of reacting sites for w.a.H electrosoprtion $\left(h_{1} / h_{2}=1.48\right.$ ). In this case, the first negative potential scan run at $0.1 \mathrm{~V} / \mathrm{s}$ from $1.35 \mathrm{~V}$ down to $0.05 \mathrm{~V}$ after the RSWPS treatment shows a large cathodic

Fig, 9. Voltammograms run at $0.1 \mathrm{~V} / \mathrm{s}$ in $1 \mathrm{M} \mathrm{H}_{2} \mathrm{SO}_{4}, 25^{\circ} \mathrm{C}$, and SEM micrographs after $17 \mathrm{~h}$ RSWPS treatment $\left(E_{1}=0.70 \mathrm{~V}, E_{\mathrm{u}}=1.35 \mathrm{~V}, f=1 \mathrm{kHz}\right)$. (a) (—) Voltammogram obtained after one cycle between $0.05 \mathrm{~V}$ and $1.50 \mathrm{~V} ;(-\ldots$,$) untreated polyfaceted sc platinum sphere. (b) SEM micrograph of$ the treated surface, scale $100 \mu \mathrm{m}$. (c,d) SEM micrographs of the region around the [100] crystallographic pole, scale: (c) $10 \mu \mathrm{m}$; (d) $1 \mu \mathrm{m}$. 
current peak at ca. $0.2 \mathrm{~V}$ probably related to the electroreduction of an oxide layer, as reported earlier [20]. The SEM images of the treated surface (Fig. 9b-d) show the formation of a metal platinum layer with a symmetric distribution compatible with the (111)-type preferred orientation [14] (Fig. 9b,c). No metal layer formation can be observed at the [111] pole crystallographic region. Furthermore, the metal layer exhibits a brush-like structure (Fig. 9d) resulting from the piling up of platinum crystallites separated by longitudinal channels.

When the RSWPS treatment proceeds at $f=7 \mathrm{kHz}(t=12 \mathrm{~h})$, it furnishes an electrode surface whose $\mathrm{H}$-electrosorption voltammogram (Fig. 10a) shows a minor increase (less than 40\%) in real surface area compared to the blank and a clear development of reacting sites for w.a.H electrosorption $\left(h_{1} / h_{2}=2.03\right)$. In addition, the voltammogram approaches those reported for either platinum (111) sc surfaces or platinum sc stepped surfaces with (111) narrow terraces under comparable conditions $[18,19,21-27]$. In this case, no oxide layer formation is detected through the first negative potential scan run at $0.1 \mathrm{~V} / \mathrm{s}$ after the RSWPS treatment. The SEM images of the treated surface (Fig. 10b,c) correspond to a very smooth surface without defects, at least at the SEM scale.

(III.3) Changes produced by an asymmetric RSWPS for $E_{l}=0.05 \mathrm{~V}$ and $E_{\mathrm{u}}=1.50 \mathrm{~V}$ at different frequencies

The influence of the symmetry $\left(\tau_{\mathrm{u}} / \tau_{1}\right.$ ratio) of the RSWPS on both $R$ and the $h_{2} / h_{1}$ ratio was studied at $0.1,1$ and $3 \mathrm{kHz}$ for $E_{1}=0.05 \mathrm{~V}$ and $E_{\mathrm{u}}=1.50 \mathrm{~V}$. For the sake of direct comparison at different $f$, results are shown as $R$ vs. $\log \tau_{\mathrm{u}} / \tau_{1}$ and $h_{2} / h_{1}$ vs. $\log \tau_{\mathrm{u}} / \tau_{1}$ plots (Fig. 11). The electrochemical treatment at $f=0.1$ $\mathrm{kHz}$ during $1 \mathrm{~h}$ in the $\tau_{\mathrm{u}} / \tau_{1}$ range between 0.5 and 4 (Fig. 11a) produces metal platinum layers with a dendritic structure whose stabilized voltammograms in the $0.05-0.60 \mathrm{~V}$ range show a slight trend for the development of reacting sites for s.a.H electrosorption (average $h_{2} / h_{1}=0.9$ ) and a gradual increase in surface area up to $\tau_{\mathrm{u}} / \tau_{1}=1.5$. As the $\tau_{\mathrm{u}} / \tau_{1}$ ratio is increased further, $R$ decreases to a minimum for $\tau_{u} / \tau_{1}=19$, and later it increases dramatically from about 4 up to 203 when $\tau_{u} / \tau_{1}$ changes from 32 to 99 . Furthermore, the $h_{2} / h_{1}$ vs. $\log \tau_{\mathrm{u}} / \tau_{1}$ plot (Fig. 11a) shows two peculiar situations, one for $\tau_{\mathrm{u}} / \tau_{1}$ equal to 0.03 and another for $\tau_{\mathrm{u}} / \tau_{1}$ equal to 19 . For $\tau_{u} / \tau_{1}=0.03$ the voltammogram of the treated surface gives a relatively high $h_{2} / h_{1}$ ratio equal to 1.22 , as expected for the development of reacting sites for s.a.H electrosorption (Fig. 12a) and the corresponding SEM micrographs exhibit a characteristic cubic geometry (Fig. 12b). Otherwise, for $\tau_{u} / \tau_{1}=19$, the $h_{2} / h_{1}$ ratio reaches a maximum value $\left(h_{2} / h_{1}=1.85\right)$ as expected for a net development of reacting sites for s.a.H electrosorption. The SEM images in this case are again consistent with the voltammetric response of the treated electrode in the $\mathrm{H}$-adatom potential range (Fig. 12c,d).

The $R$ and $h_{2} / h_{1}$ vs. $\log \tau_{\mathrm{u}} / \tau_{1}$ plots for $f=1 \mathrm{kHz}$ (Fig. 11b) and $f=3 \mathrm{kHz}$ (Fig. $11 \mathrm{c})$ show that the $\tau_{\mathrm{u}} / \tau_{1}$ range corresponding to the sharp increase in $R$ approaches 1 (symmetric waveform) as $f$ increases. On the other hand, for any $f$ the range of 


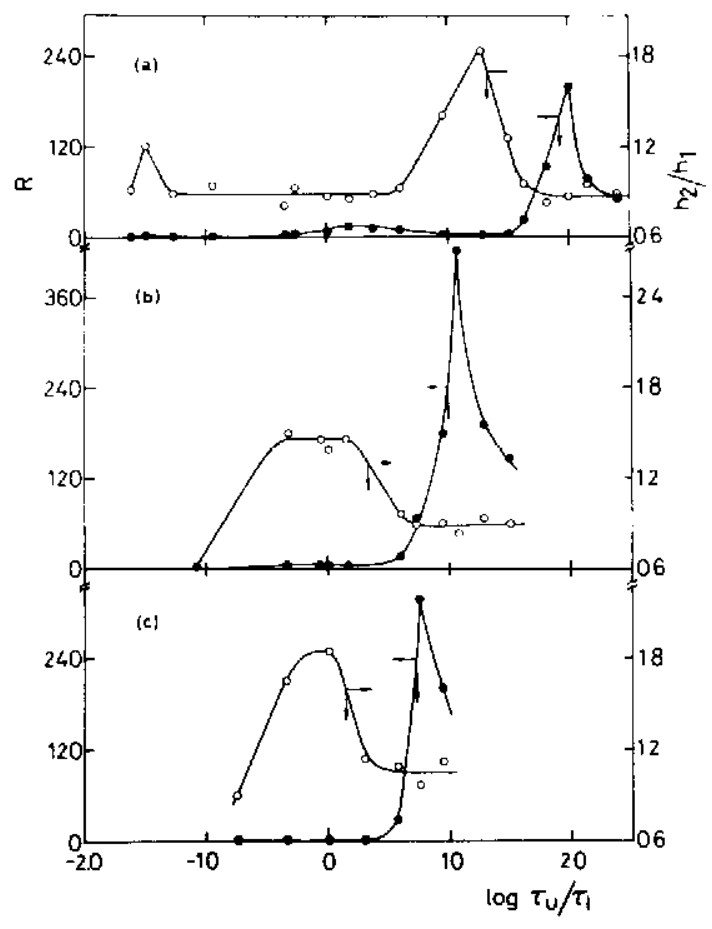

Fig. 11. Dependence of $R$ and $h_{2} / h_{1}$ on $\log \tau_{\mathrm{u}} / \tau_{1}$ at different $f$ derived from stabilized voltammograms run at $0.1 \mathrm{~V} / \mathrm{s}$ between $0.05 \mathrm{~V}$ and $0.60 \mathrm{~V}$ in $1 \mathrm{M} \mathrm{H}_{2} \mathrm{SO}_{4}, 25^{\circ} \mathrm{C}$. after $1 \mathrm{~h}$ RSWPS treatment ( $E_{1}=0.05$ V. $E_{\mathrm{u}}=1.50 \mathrm{~V}$ ). $f=$ (a) 0.1 ; (b) 1 ; (c) $3 \mathrm{kHz}$.

$\tau_{\mathrm{u}} / \tau_{1}$ associated with the highest value of $h_{2} / h_{1}$ is around 1 , as reported earlier [11]. Furthermore, under these conditions the development of reacting sites for s.a.H electrosorption, as followed through the $h_{2} / h_{1}$ ratio, is favoured upon increasing $f$.

The RSWPS treatment made in the $0.1-3 \mathrm{kHz}$ range for $\tau_{\mathrm{u}} / \tau_{1}$ ratios related to the peaked $R$ values accumulates an oxide layer on the electrode surface. This layer is electroreduced through potential cycling at $0.1 \mathrm{~V} / \mathrm{s}$ between $0.60 \mathrm{~V}$ and $0.05 \mathrm{~V}$ (Fig. 13a). The stabilized voltammogram in the $\mathrm{H}$-adatom potential range exhibits a dramatic increase in voltammetric charge and slight development of reacting sites for s.a.H electrosorption (Fig. 13b). The corresponding SEM micrographs show a metal platinum layer with a typical cauliflower structure consisting of large and small globules (Fig. 13c,d). Surprisingly, this platinum structure is similar to that described earlier for the surfaces resulting from the electroreduction of a platinum oxide layer formed after applying to pc platinum a symmetric RSWPS at $1 \mathrm{kHz}$ but at $E_{\mathrm{u}}>2.1 \mathrm{~V}[5,12,28]$.

The IR spectra of anodic layers produced by the different electrochemical treatments, namely, for (a) $E_{1}=0.05 \mathrm{~V}, E_{\mu}=1.50 \mathrm{~V}, f=1 \mathrm{kHz}, \tau_{\mathrm{u}} / \tau_{1}=12, t=3 \mathrm{~h}$ and (b) $E_{1}=0.05 \mathrm{~V}, E_{\mathrm{u}}=2.50 \mathrm{~V}, f=2 \mathrm{kHz}, \tau_{\mathrm{u}} / \tau_{1}=1, t=3 \mathrm{~h}$, were compared to 

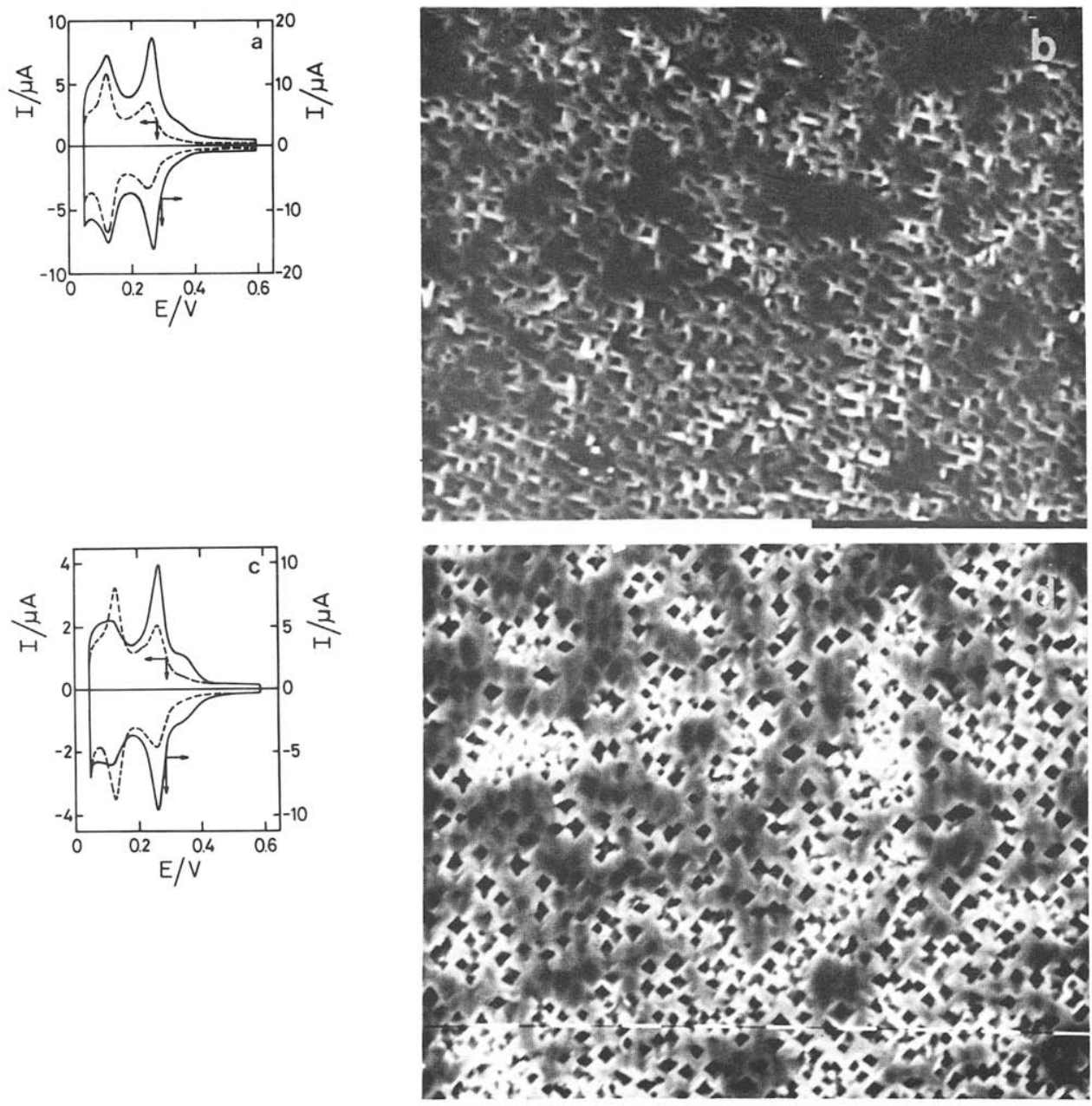

Fig. 12. Voltammograms nun at $0.1 \mathrm{~V} / \mathrm{s}$ in $1 \mathrm{M} \mathrm{H}_{2} \mathrm{SO}_{4}, 25^{\circ} \mathrm{C}$, and SEM micrographs after $1 \mathrm{~h}$ RSWPS treatment $\left(E_{\mathrm{l}}=0.05 \mathrm{~V}, E_{\mathrm{u}}=1.50 \mathrm{~V}, f=0.1 \mathrm{kHz}\right)$ for $\tau_{\mathrm{u}} / \tau_{1}=0.03(\mathrm{a}, \mathrm{b})$ and $\tau_{\mathrm{u}} / \tau_{\mathrm{l}}=19$ (c,d). (a,c) (- ) Voltammograms (third cycle) run between $0.05 \mathrm{~V}$ and $0.60 \mathrm{~V}$; ( - _- -.) untreated polyfaceted sc platinum sphere. (b,d) SEM micrographs of the treated surfaces, scale: (b) $10 \mu \mathrm{m}$; (d) $1 \mu \mathrm{m}$.

that of $\mathrm{PtO}_{2}$ prepared chemically according to the method described elsewhere [29]. The three IR spectra exhibited the band at $600 \mathrm{~cm}^{-1}$ characterizing the stretching of the $\mathrm{PtO}$ bond, in coincidence with that of a $\mathrm{PtO}_{2}$ standard [30].

(III.4) Changes produced by an asymmetric RSWPS for $E_{l}=0.70 \mathrm{~V}$ and $E_{u}=1.35 \mathrm{~V}$ at a constant frequency

The RSWPS treatment for $1 \mathrm{~h}$ with $E_{1}=0.70 \mathrm{~V}, E_{\mathrm{u}}=1.35 \mathrm{~V}$ and $f=1 \mathrm{kHz}$ in the $\tau_{\mathrm{u}} / \tau_{1}$ range between 0.3 and 3 produces a remarkable change in $R$, with a 

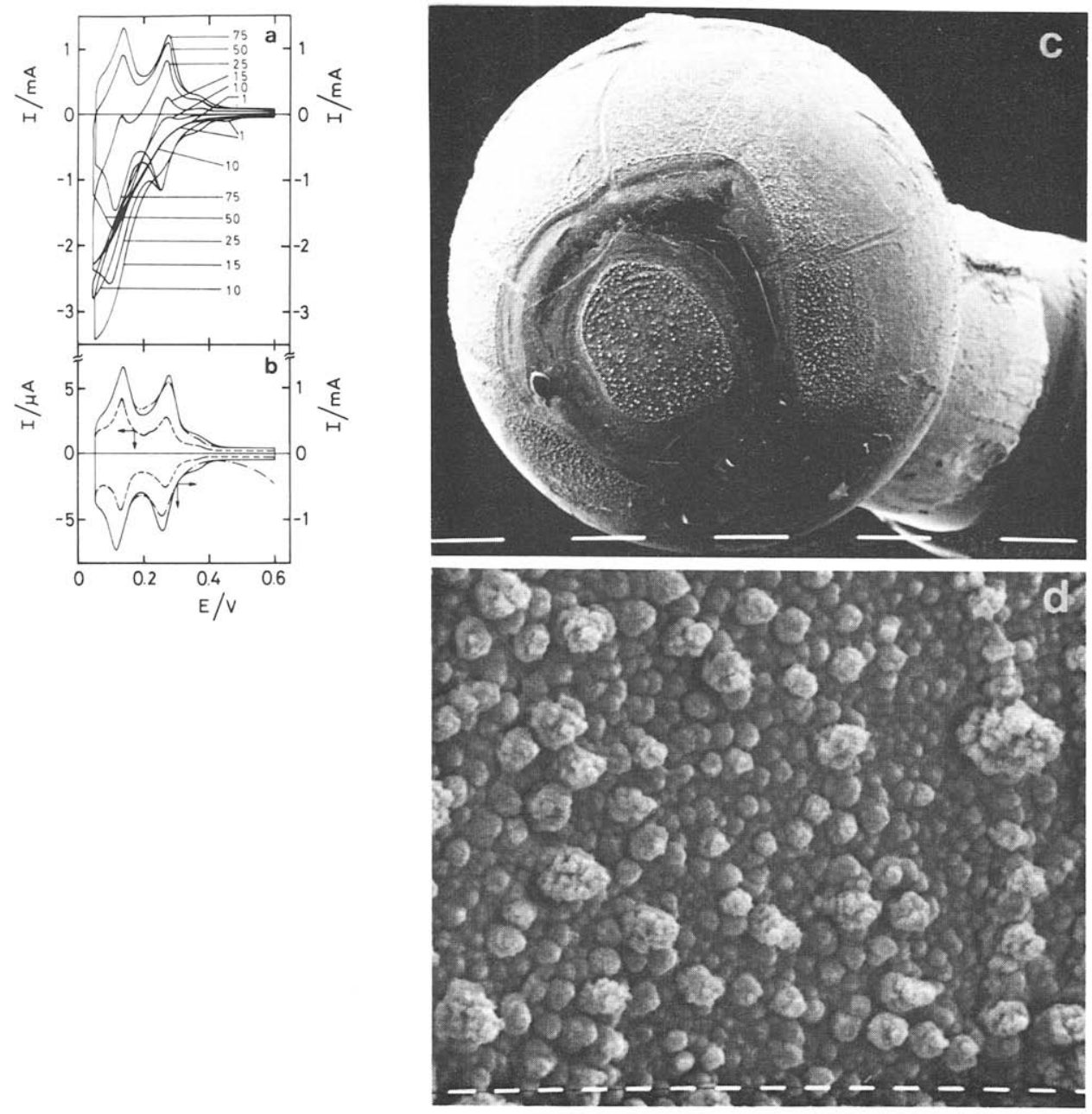

Fig. 13. Voltanmograms run at $0.1 \mathrm{~V} / \mathrm{s}$ in $1 \mathrm{M} \mathrm{H}_{2} \mathrm{SO}_{4}, 25^{\circ} \mathrm{C}$, and SEM micrographs after $1 \mathrm{~h}$ RSWPS treatment $\left(E_{1}=0.05 \mathrm{~V}, E_{\mathrm{u}}=1.50 \mathrm{~V}, f=1 \mathrm{kHz}, \tau_{\mathrm{u}} / \tau_{1}=12\right)$. (a) Transition from the first negative potential scan to the stabilized voltammogram (75th scan). (b) ( - Stablized voltummogram run between $0.05 \mathrm{~V}$ and $0.60 \mathrm{~V} ;(-\cdot-\cdot)$ voltammogram obtained after one cycle between $0.05 \mathrm{~V}$ and 1.50 $V ;(-\ldots-)$ untreated polyfaceted se platinum sphere. (c,d) SEM micrographs of the treated surface, scale: (c) $100 \mu \mathrm{m}$; (d) $1 \mu \mathrm{m}$.

maximum $R$ value equal to 5.6 for $\tau_{\mathrm{u}} / \tau_{1}=1$ (Fig. 14). The electrode surfaces obtained in this $\tau_{\mathrm{p}} / \tau_{1}$ range present a brush-like structure as that already shown in Fig. 9c,d. Furthermore, the voltammograms of these electrode surfaces involve $h_{1} / h_{2}$ ratios approaching that expected for the development of reacting sites for w.a.H electrosorption. For $\tau_{\mathrm{u}} / \tau_{1}>3$, the $h_{1} / h_{2}$ ratio attains a large constant value 


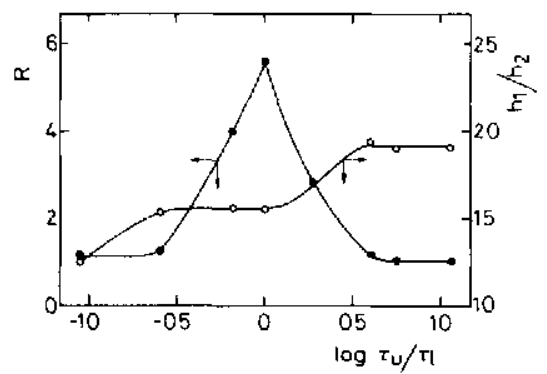

Fig. 14. Dependence of $R$ and $h_{1} / h_{2}$ on $\log \tau_{\mathrm{u}} / \tau_{1}$ derived from voltammograms run at $0.1 \mathrm{~V} / \mathrm{s}$ following one cycle between $0.05 \mathrm{~V}$ and $1.50 \mathrm{~V}$ in $1 . M \mathrm{H}_{2} \mathrm{SO}_{4}, 25^{\circ} \mathrm{C}$. after $1 \mathrm{~h}$ RSWPS treatment $\left(E_{1}=0.70 \mathrm{~V}, E_{\mathrm{u}}=1.35 \mathrm{~V}, f=1 \mathrm{kHz}\right.$ ).

and the corresponding values of $R$ become practically equal to one. Under these conditions, no oxide layer accumulation can be detected through the first negative potential scan run at $0.1 \mathrm{~V} / \mathrm{s}$ after the RSWPS treatment. Inspection of the SEM images show very smooth surfaces which are similar to that already depicted in Fig. $10 \mathrm{~b}, \mathrm{c}$. From these data one can conclude that the development of reacting sites for w.a.H electrosorption in the plateau regions of the $h_{1} / h_{2}$ vs. $\log \tau_{u} / \tau_{1}$ plot (Fig. 14) is likely to involve different distinguishable mechanisms.

\section{(IV) DISCUSSION}

When a platinum electrode is subjected to a periodic potential treatment in the $0.05-1.50 \mathrm{~V}$ range, the resulting electrode surface exhibits changes in real surface area, crystallographic orientation and morphology, according to the symmetry, $E_{1}$, $E_{\mathrm{u}}$ and $f$ values of the potential perturbation. These changes can be produced by setting the $E_{1}$ and $E_{\mathrm{u}}$ values of the RSWPS at the negative and at the positive potential sides, respectively, of the standard equilibrium potential of the following reactions $[20,31]$ :

$$
\begin{array}{lll}
\mathrm{Pt}^{2+}+2 e^{-} & =\mathrm{Pt} & E^{\circ}=1.19 \mathrm{~V} \\
\mathrm{Pt}(\mathrm{OH})+\mathrm{H}^{+}+e^{-} & =\mathrm{Pt}+\mathrm{H}_{2} \mathrm{O} & E^{\circ}=0.85 \mathrm{~V} \\
\mathrm{PtO}+2 \mathrm{H}^{+}+2 e^{-} & =\mathrm{Pt}+\mathrm{H}_{2} \mathrm{O} & E^{\circ}=0.98 \mathrm{~V} \\
\mathrm{PtO}_{2}+2 \mathrm{H}^{+}+2 e^{-} & =\mathrm{PtO}+\mathrm{H}_{2} \mathrm{O} & E^{\circ}=1.045 \mathrm{~V} \\
\mathrm{PtO}_{2}+4 \mathrm{H}^{+}+2 e^{-} & =\mathrm{Pt}^{2+}+2 \mathrm{H}_{2} \mathrm{O} & E^{\circ}=0.84 \mathrm{~V}
\end{array}
$$

Hence, for any $E_{\mathrm{u}}$ value, $\mathrm{O}$-containing surface species and soluble $\mathrm{Pt}^{2+}$ species can be formed. Similarly, for any $E_{1}$ value, both soluble $\mathrm{Pt}^{2+}$ species and $\mathrm{O}$-containing surface species can be totally or partially electroreduced, yielding a new platinum electrode surface. Furthermore, the oxygen evolution reaction is thermodynamically feasible for all the $E_{\mathrm{u}}$ values employed in the RSWPS treatment. On the other hand, 
$\mathrm{H}$ electroadsorption takes place for the lowest $E_{1}$ value, that is $E_{1}=0.05 \mathrm{~V}$. When the $E_{1}$ value lies in the $\mathrm{H}$-adatom potential range, the development of reacting sites for s.a.H electrosorption is favoured, whereas when the $E_{1}$ value is set more positive than $0.4 \mathrm{~V}$, the development of reacting sites for w.a.H electrosorption is accomplished. Taking into account the complexity of the different processes which are involved in the potential range of the RSWPS treatment, the following discussion is based on the reactions prevailing in the overall process under definite ranges of operating conditions.

(IV.I) Case 1. Changes in the electrode surface structure produced mainly by the $\mathrm{Pt}^{2+} / \mathrm{Pt}$ electrochemical reaction

When $E_{1}=0.05 \mathrm{~V}$ and $E_{\mathrm{u}}=1.50 \mathrm{~V}$ different processes associated with the $\mathrm{Pt}^{2+} / \mathrm{Pt}$ and platinum oxide/ $\mathrm{Pt}$ redox couples can occur. However, for the present case any oxide layer formed at $E_{\mathrm{u}}$ is completely electroreduced at $E_{1}$ during each cycle. Hence, each RSWPS cycle involves mainly the electrodissolution of platinum as $\mathrm{Pt}^{2+}$, through the $\mathrm{Pt}(\mathrm{OH})_{\mathrm{add}}$ intermediate [20] during $\tau_{\mathrm{u}}$ (positive half-cycle) and the reverse process during $\tau_{1}$ (negative half-cycle). Accordingly, during the RSWPS treatment a fluctuating concentration gradient of soluble platinum species adjacent to the electrode surface is established through a complex pulsating diffusional boundary layer whose average thickness, $\delta_{\mathrm{p}}$ [32], depends inversely on the square root of the frequency of the periodic potential [33]. The processes occurring during $\tau_{\mathrm{u}}$ imply rapid electron transfer reactions followed by a transport of soluble species from the metal surface to the solution side assisted by the local electric field. On the other hand, the processes occurring during $\tau_{1}$ correspond to a transport of soluble species towards the metal surface, affected also by the local electric field, followed by fast electron transfer reactions and adatom reaccommodation, as given in metal electrodeposition mechanisms $[34,35]$. Thus, in this case, the overall process yields a gradual accummulation of soluble platinum species in the bulk solution, as reported recently [17]. Furthermore, the amount of platinum species going in solution per cycle decreases as $f$ increases because of the dependence of $\delta_{\mathrm{p}}$ on $f[33,36]$.

For low frequency symmetric RSWPS, that is, $0.025 \mathrm{kHz} \leqslant f \leqslant 0.1 \mathrm{kHz}$, as $\delta_{\mathrm{p}}$ is of the order of $10^{-3} \mathrm{~cm}$, approaching values reported for stationary electrolysis conditions [36], the overall process is diffusion controlled. For this low $f$ range the RSWPS treatment provides the largest increase in $R$ and only a minor development of reacting sites for s.a.H electrosorption. Correspondingly, the morphology of the electrodeposited platinum layer involves a dendritic structure. These results are in agreement with those corresponding to conventional potentiostatic electrodeposition of many metals [35].

On the other hand, as $f$ increases, $\delta_{\mathrm{p}}$ decreases to values which are smaller than those found for mass transport rate controlled reactions. Thus, for instance, for $f$ in the 1-6 kHz range, $\delta_{\mathrm{p}}$ lies between $10^{-4}$ and $10^{-5} \mathrm{~cm}$ and the kinetics of the overall process change progressively from diffusion to activation control and become more dependent on the properties of each crystallographic face. Hence, for $1 \mathrm{kHz} \leqslant f \leqslant 6$ 
$\mathrm{kHz}$, that is, for $0.08 \mathrm{~ms} \leqslant \tau_{\mathrm{u}}=\tau_{1} \leqslant 0.5 \mathrm{~ms}$, the dendritic metal layer is no longer formed and the morphology of the resulting surface gradually changes to that of a faceted surface with the development of reacting sites for s.a.H electrosorption accompanied by a minor change in $R$ [11]. The particular situation corresponding to a symmetric RSWPS at $f \geqslant 6 \mathrm{kHz}$ is further discussed in Case 4.

This kinetic explanation also accounts for the two peculiar situations arising, at $f=0.1 \mathrm{kHz}$, for $\tau_{\mathrm{u}} / \tau_{1}$ ratios equal to 0.03 and 19 (Figs. 11 and 12), comprising $\tau_{\mathrm{u}}=0.3 \mathrm{~ms}$ and $\tau_{\mathrm{l}}=0.5 \mathrm{~ms}$, respectively, that is, $\tau$ values shorter than the half-lifetime of $\mathrm{Pt}(\mathrm{OH})_{\mathrm{ad}}$ species $[4,5,37]$. For $\tau_{\mathrm{u}}=0.3 \mathrm{~ms}$, only dissolved platinum species which lie within the thickness $\delta_{\mathrm{p}} \approx 10^{-4} \mathrm{~cm}$ adjacent to the electrode surface can participate in reactions at the electrode surface. The same situation is also valid for $\tau_{1}=0.5 \mathrm{~ms}$. Therefore, the kinetics of the overall process are determined largely by the shortest half-cycle time and under these circumstances the reaction also becomes activation controlled. These events result in a new platinum surface involving a predominant electrochemical faceting with a minor increase in $R$.

(IV.2) Case 2. Changes in the electrode surface structure produced through electrochemical reactions involving platinum oxide lavers

According to thermodynamics (reactions 2-5) different anodic oxide layers can be formed on platinum in acid at $E_{\mathrm{u}}=1.35 \mathrm{~V}$. Thus, for $E_{1}=0.70 \mathrm{~V}, E_{\mathrm{u}}=1.35 \mathrm{~V}$ and $f=1 \mathrm{kHz}$, the RSWPS treatment yields the accumulation of an oxide layer [20], whose electroreduction charge can be evaluated through the first voltammetric half-cycle at $0.1 \mathrm{~V} / \mathrm{s}$ from $1.35 \mathrm{~V}$ to $0.05 \mathrm{~V}$. The formation of oxide layers with a symmetric RSWPS at $f=1 \mathrm{kHz}$, that is, for values of $\tau_{u}=\tau_{1}$ of the order of the half-life time of the $\mathrm{Pt}(\mathrm{OH})_{\text {ad }}$ intermediate. involves no significant contribution by an ageing process. This type of anodic layer appears for different metals subjected to periodic potential cycling [4-6,38,39]. The platinum surface resulting from the electroreduction of those oxide layers (Fig. 9) corresponds to a brush-like structured layer with a large increase in $R$, which exhibits a symmetry pattern compatible with the development of a (111)-type preferred orientation [14]. The latter is assisted by the fact that no $\mathrm{H}$-adatoms are present at $E_{\mathrm{J}}=0.70 \mathrm{~V}$ [11]. Furthermore, when $f$ is increased progressively from $1 \mathrm{kHz}$ to $7 \mathrm{kHz}$, the brush-like structure layer gradually disappears and correspondingly, a decrease in $R$ and a progressive development of reacting sites for w.a.H electrosorption, as followed through the $h_{1} / h_{2}$ ratio, can be observed (Fig. 7). In this way, a limiting situation is found for $f \geqslant 6 \mathrm{kHz}$, a frequency at which no oxide layer accumulation can be produced through the RSWPS treatment, where the resulting platinum surface becomes very smooth, exhibiting a SEM pattern and voltammetric characteristics similar to those reported for platinum (111) sc surfaces. This situation is discussed further on for Case 4.

It should be noticed that for a symmetric RSWPS, by setting $E_{1}=0.70 \mathrm{~V}$, $E_{\mathrm{u}}=1.35 \mathrm{~V}$ but $f \leqslant 0.25 \mathrm{kHz}$, only a slight increase in $R$ and electrochemical faceting with a minor development of reacting sites for s.a.H electrosorption are observed. The morphology of the resulting surface (Fig. $8 \mathrm{c}, \mathrm{d}$ ) is comparable to that 
produced by chemical etching. In this case, no oxide layer accumulation can be detected after the RSWPS treatment probably because ageing processes of the O-containing layer [40] formed at $E_{\mathrm{u}}$ hinder further oxide growth. Under these conditions the situation already encountered in Case 1 is approached.

Let us now consider the influence of the RSWPS symmetry on the characteristics of the resulting surface. For $E_{1}=0.70 \mathrm{~V}, E_{\mathrm{u}}=1.35 \mathrm{~V}, f=1 \mathrm{kHz}$ and $4 \leqslant \tau_{\mathrm{u}} / \tau_{1} \leqslant 1.15$ (Fig. 14), that is, for $\tau_{\mathrm{u}}$ between $0.8 \mathrm{~ms}$ and $0.92 \mathrm{~ms}$, surprisingly no oxide layer growth can be detected despite the fact that $\tau_{\mathrm{u}}>\tau_{1}$. In this case, as only reactions at the O-monolayer level take place [40], no increase in $R$ but a definite development of reacting sites for w.a.H electrosorption is accomplished. Otherwise, data derived for $\tau_{u} / \tau_{1}=0.09\left(\tau_{u}=0.08 \mathrm{~ms}\right)$ indicate again practically no oxide layer formation. Accordingly, no increase in $R$ but only a slight change in the relative distribution of $\mathrm{H}$-adatom current peaks can be observed after the electroreduction cycle.

(IV.3) Case 3. Changes in the electrode surface structure produced through electrochemical reactions involving a thick $\mathrm{PtO}_{2}$-type layer

When the RSWPS covers the range from $E_{1}=0.05 \mathrm{~V}$ up to $E_{\mathrm{u}}=1.50 \mathrm{~V}$ and the $\tau_{\mathrm{u}} / \tau_{1}$ ratio exceeds a certain threshold value which depends on $f$ (Fig. 11), a thick oxide layer is formed which, according to ex-situ analysis, corresponds to $\mathrm{PtO}_{2}$. In this case. the value of $E_{\mathrm{u}}$ exceeds the thermodynamic potentials of reactions (4) and (5). The voltammetric electroreduction of the oxide layer furnishes an electrode surface with a remarkable increase in $R$. Furthermore. the $\tau_{\mathrm{u}} / \tau_{1}$ ratio associated with the largest increase in $R,\left(R_{\mathrm{M}}\right)$, also depends on $f$ (Fig. 11). Thus, when $f \rightarrow \infty, R_{\mathrm{M}}$ is approached for $\tau_{\mathrm{u}} / \tau_{1} \rightarrow 1$, whereas when $f$ decreases, the value of $R_{\mathrm{M}}$ is attained for increasing $\tau_{\mathrm{u}} / \tau_{1}$ ratios. As reported previously $[4,10]$, the growth of the thick platinum oxide layer under symmetric RSWPS takes place in the absence of ageing effect. This situation also prevails for asymmetric RSWPS involving a short $\tau_{1}$ value which contributes to maintain continuously a fresh platinum surface and to avoid local acidification and water depletion at the metal/solution interface. The structure of the platinum electroreduced layer, as revealed through SEM micrographs, consists of sphere-like sticking clusters like that found recently for electroreduced platinum and gold on the basis of scanning electron tunneling microscopy imaging $[12,41]$.

(IV.4) Case 4. Electrode processes at the surface level promoting preferred crystallographic orientation without increase in surface area

For symmetric RSWPS in the $6 \mathrm{kHz} \leqslant f \leqslant 20 \mathrm{kHz}$ range, the $\tau_{\mathrm{u}}$ and $\tau_{1}$ values are much shorter than the average half-life time of the $\mathrm{Pt}(\mathrm{OH})_{\text {ad }}$ intermediate produced in the initial electron transfer reaction (2). Under these conditions, the formation and accumulation of any oxide layer should be practically cancelled. Likewise, as $f$ increases, the contribution of local fast platinum electrodissolution and electrodeposition processes should become less important in favour of a new process 
which can be described as follows. During the positive half-cycle the main process should now be attributed to the loosening of platinum atoms of the first metal surface layers. These atoms are then able to diffuse on the surface over a distance sufficiently large to facilitate their reaccomodation at growing sites (steps, kinks) during the negative half-cycle. Thus, as $f$ increases, the overall process becomes strongly dependent on both the surface diffusion coefficient of platinum adatoms and the distribution and properties of growing sites. Hence, the treated surface develops electrochemical faceting with no increase in surface area.

(IV.5) Case 5. Electrode processes at the surface level apparently promoting a decrease in surface heterogeneity

Another interesting situation arises when the frequency of the symmetric periodic potential perturbation exceeds approx. $20 \mathrm{kHz}$. Some preliminary data obtained under this condition were already advanced in a recent paper [11]. In this case, conventional electrochemical reactions, as given by eqns. (1)-(5), are, in principle, impeded and the surface diffusion of platinum atoms should only imply displacements shorter than a certain critical distance required to allocate metal atoms at growing edges such as steps or kinks [34]. For this extreme condition one should expect short range atom reaccomodation effects such as those corresponding to annihilation of defects at solid surfaces $[10,11,42]$ instead of the type of preferred crystallographic orientation such as that reported recently on the nanometer scale [43]. Therefore, the surface heterogeneity is expected to decrease and the treated surface should exhibit no increase in roughness and a sharper voltammetric distinction of the different crystallographic faces already present on the original platinum surface. Voltammetric runs for platinum surfaces after RSWPS treatment ( $E_{1}=0.25$ V, $E_{\mathrm{u}}=1.25 \mathrm{~V}$ ) at $20 \mathrm{kHz}$ (Fig. 4d, ref. 11) show acute $\mathrm{H}$-adatom current peaks and no increase in the related voltammetric charge, which correlates satisfactorily with the proposed physical mechanism. A more detailed description of this mechanism will be discussed in a forthcoming publication.

\section{ACKNOWLEDGEMENTS}

This work was supported by the Universidad Nacional de La Plata, the Consejo Nacional de Investigaciones Cientificas y Técnicas, the Comisión de Investigaciones Cientificas (Provincia de Buenos Aires) and the Third World Academy of Science (TWAS). W.E. Triaca thanks TWAS for Research Grant No. 87-15. The authors are indebted to Dr. M. Ipohorski (CONEA) for making available the facilities for obtaining the SEM patterns.

\section{REFERENCES}

1 S. Gilman, J. Electroanal. Chem., 9 (1965) 276.

2 T. Biegler, J. Electrochem. Soc., 116 (1969) 1131.

3 R. Woods in A.J. Bard (Ed.), Electroanalytical Chemistry, Vol. 9. Arnold Press, London, 1977, p. 2. 
4 A.C. Chalvo, W.E. Triaca and A.J. Arvia, J. Electroanal. Chem., 146 (1983) 93.

5 A.C. Chialvo, W.E. Triaca and A.J. Arvia, J. Electroanal. Chem., 171 (1984) 303.

6 A.C. Chialvo, W.E. Triaca and A.J. Arvia, J. Electroanal. Chem., 237 (1987) 237.

7 R.M. Cerviño, W.E. Triaca and A.J. Arvia, J. Electroanal. Chem., 182 (1985) 51.

8 J.C. Canullo, W.E. Triaca and A.J. Arvia, J. Electroanal. Chem., 175 (1984) 337.

9 R.M. Cerviño. W.E. Triaca and A.J. Arvia, J. Electrochem. Soc., 132 (1985) 266.

10 A.J. Arvia, J.C. Canullo, E. Custidiano, C.L. Perdricl and W.E. Triaca. Electrochim. Acta, 31 (1986) 1359.

11 W.E. Tnaca, T. Kessler, J.C. Canullo and A.J. Arvia, J. Electrochem. Soc., 134 (1987) 1165.

12 L. Vázquez, J. Gómez, A.M. Baró, N. Garcia, M.L. Marcos, J. González-Velasco, J.M. Vara Cuadrado, A.J. Arvia, J. Presu, A. Garcia and M. Aguilar, J. Am. Chem. Soc., 109 (1987) 1730.

13 A. Visintin, W.E. Triaca and A.J. Arvia, J. Electroanal. Chem., 221 (1987) 239.

14 J.C. Canullo, W.E. Traca and A.J. Arvia. J. Electroanal. Chem., 200 (1986) 397.

15 J.C. Canullo, Y. Uchida, G. Lehmpfuhl. T. Twomey and D.M. Kolb. Surf. Sci., in press.

16 J. Clavilier, R. Durand, G. Guinet and R. Faure, J. Electroanal. Chem., 127 (1981) 281.

17 C.L. Scortıchuni and C.N. Reilley, J. Electroanal. Chem., 139 (1982) 233.

18 J. Clavilier, D. Armand, S.G. Sun and M. Petit, J. Electroanal. Chem.. 205 (1986) 267.

19 A.V. Tripković and R.R. Adžić, J. Electroanal. Chem.. 205 (1986) 335.

20 C.L. Perdriel. W.E. Triaca and A.J. Arvia, J. Electroanal. Chem.. 205 (1986) 279.

21 F.G. Will. J. Electrochem. Soc., 112 (1965) 451.

22 P.N. Ross, Jr., J. Electroanal. Chem., 76 (1977) 139.

23 A.T. Hubbard, R.M. Ishikawa and J. Katekaru, J. Electroanal. Chem., 86 (1978) 271

24 K. Yamamoto, D.M. Kolb, R. Kötz and G. Lehmpfuhl, J. Electroanal. Chem., 36 (1979) 233.

25 P.N. Ross, Jr., J. Electrochem. Soc., 126 (1979) 67.

26 J. Clavilier, R. Faure, G. Guinet and R. Durand, J. Electroanal. Chem., 107 (1980) 205.

27 F.E. Woodward, C.L. Scortichuni and C.N. Reilley, J. Electroanal. Chem., 151 (1983) 109.

28 S.M. Piovano, A.C. Chialvo, W.E. Triaca and A.J. Arvia, J Appl. Electrochem., 17 (1987) 147.

29 G. Brauer, Handbuch der Präparativen Anorganischen Chemie, Vol. 2, Ferdinand Enke, Stuttgart, 1962 , p. 1370.

30 The Sadtler Standard Spectra, Vol. 3. Sadtler Research Laboratories. Philadelphia, 1967.

31 A.J. Bard, R. Parsons and J. Jordan (Eds.), Standard Potentials in Aqueous Solutions, Marcel Dekker, New York, 1985, p. 353.

32 S.L. Marchtano and A.J. Arvia, in preparation.

33 A.R. Despic and K.I. Popov, J. Appl. Electrochem., 1 (1971) 275.

34 E.B. Budevski in B. Conway, J.O'M. Bockris, E. Yeager, S.U.M. Khan and R.K. White (Eds.), Comprehensive Treatise of Electrochemıstry, Vol. 7, Plenum Press, New York, 1983, p. 399.

35 A.R. Despic in ref. 34, p. 451.

36 N. Ibl, Surf. Technol., 10 (1980) 81.

37 B.E. Conway, H. Angerstein-Kozlowska, F.C. Ho, J. Klınger, B. MacDougall and S. Gottesfeld, Faraday Discuss. Chem. Soc., 56 (1973) 210.

38 L.D. Burke and T.A.M. Twomey, J. Electroanal. Chem., 162 (1984) 101.

39 A. Visintin. A.C. Chialvo, W.E. Triaca and A.J. Arvia, J. Flectroanal. Chem., 225 (1987) 227.

40 M.E. Folquer, J.O. Zerbino, N.R. de Tacconi and A.J. Arvia, J. Electrochem. Soc., 126 (1979) 592.

41 J. Gómez, L. Vázquez, A.M. Baró, C. Alonso, E. González, J. González-Velasco and A.J. Arvıa, J. Electroanal. Chem., in press.

42 A.C. Chialvo, W.E. Triaca and A.J. Arvia, Anal. Asoc. Quim. Arg., 73 (1985) 23.

43 J. Gómez. L. Vázquez, A.M. Baró, N. Garcia, C.L. Perdriel, W.E. Triaca and A.J. Arvia, Nature (London), 323 (1986) 612. 